\title{
An indefinite maze: on the distribution of partitives and bare nouns in the Northern Italian dialects
}

\section{Francesco Pinzin}

Goethe Universität Frankfurt a.M.

pinzinfrancesco@gmail.com

\section{Cecilia Poletto}

Goethe Universität Frankfurt a.M.

Poletto@em.uni-frankfurt.de

Received: 15-03-21

Accepted: 30-09-21

Published: 22-02-22

How to cite: Francesco Pinzin \& Cecilia Poletto. 202x. An indefinite maze: on the distribution of partitives and bare nouns in the Northern Italian dialects. RLLT17, eds. Ora Matushansky, Laurent Roussarie, Michela Russo, Elena Soare \& Sophie Wauquier. Special issue of Isogloss Open Journal of Romance Linguistics 8(2)/20, 1-23.

DOI: https://doi.org/10.5565/rev/isogloss. 130

\section{Abstract}

Some Romance languages, like Spanish, encode narrow scope indefinite objects without any over determiner (Bare Nouns; como pan 'I eat bread'), while others, like French, require the insertion of an overt prenominal marker, labeled Partitive Article (PA; je mange du pain 'I eat bread'). This asymmetry has been related to overt number marking on the noun (Delfitto \& Schroter, Stark 2016 a.o.), leading to the hypothesis that number morphs on $\mathrm{N}$ license indefinite arguments and that PAs appear in those languages in which they are absent. Languages as Italian, in which narrow scope indefinites can be introduced both by BNs and PAs, challenge this hypothesis. By enlarging the view to Northern Italian Dialects, we update the correlation with number marking (the relevant 
factor being the absence of number morphs on masculine Ns) and show that Italian-like languages are not problematic, once we develop an analysis of the alternation between PAs and BNs in these languages in terms of two kinds of indefinites, differentiated by the presence/absence (PAs/BNs) of a feature (tentatively identified as a Choice function, Reinhart 1997).

Keywords: Partitive articles, bare nouns, indefinites, Italian dialects, microvariation.

\section{Introduction}

The competition between indefinite Partitive Articles and Bare Nominals for the realization of indefinite arguments is a longstanding debate in Romance linguistics (Delfitto \& Schroter 1991, Stark 2016, Gerards \& Stark 2020). French and Spanish represent a clear example of this opposition. To express the least marked kind of indefinite arguments, Spanish only employs Bare Nouns (BNs), while French only employs indefinite Partitive Articles (PAs), which we operationally define as indefinite markers homophonous with the conflation of the preposition $d e$ 'of' and the definite article. ${ }^{1}$

$\begin{array}{ll}\text { Como } & \text { pan/cerezas. } \\ \text { eat.1SG } & \text { bread/cherries } \\ \text { Je } & \text { mange } *(\text { du }) \text { pain/ } \\ \text { I } & \text { eat.1SG of.the.M.SG bread/ } \\ \text { 'I eat bread/cherries.' }\end{array}$

*(des) cerises. of.the.PL cherries

(Spanish)

(French)

French does not allow for the use of BNs. ${ }^{2}$ On the contrary, indefinite PAs are not available in Spanish, although the form does exist. The insertion of a morphologically parallel form as del/de las (the conflation of de 'of' and the definite article el/las 'the.M.SG/F.PL') in (1) leads to a partitive interpretation 'I eat some of the bread/cherries', not to an indefinite one.

This crosslinguistic competition between $\mathrm{BNs}$ and PAs correlates with the typology of number marking on the noun (as noted by several authors, see Delfitto \& Schroter 1991, Stark 2016, Stark \& Gerards 2020, Gerards \& Starke 2020). If we only considered Spanish and French, a plausible generalization could be that the absence of number marking on $\mathrm{N}$ leads to the necessity of using PAs, while the presence of number marking on $\mathrm{N}$ leads to the presence of BNs.

However, a broader crosslinguistic perspective across Romance shows that this rather straightforward correlation does not hold as such. This is so, because some Romance languages have number marking on N, like Spanish does, but can express indefinites both as BNs and as PAs. An example of such a language is Italian.

1 Compare the following examples with (1)-(2).

i. Le jouet du garçon / des garçons. the toy of.the.M.SG boy / of.the.PL boys

'The toy of the boy / boys.'

2 For a general review of the status of BNs in French, especially in predicative position, see Beyssade (2011). 


$\begin{array}{lll}\begin{array}{l}\text { Mangio } \\ \text { eat.1SG bane. }\end{array} & & \text { (Italian) } \\ \text { Mangio del } & \text { pread } & \text { (Italian) } \\ \text { eat.1SG of.the.M.SG } & \text { bread } & \end{array}$

'I eat bread'

Note that the interpretation of (4) in Italian is not that of a real partitive ('I eat some of the bread') but an indefinite one ('I eat bread', see Chierchia 1997, Longobardi 2001, Storto 2003, Zamparelli 2008, Cardinaletti \& Giusti 2016). This kind of pattern is problematic for a "dicothomic" approach as the one briefly sketched above. If a language in which number is marked on $\mathrm{N}$ can have both BNs and indefinite PAs, the direct correlation between number marking on $\mathrm{N}$ and the "only BNs" pattern (Spanish) cannot hold, at least in the simplified version proposed in the literature we briefly sketched above. An approach to this issue has been proposed in Stark (2016), who treats the Italian pattern in terms of optionality: Italian possesses peculiar number markers - i.e. portmanteaus fusing together number and gender (ragazz-o m.sg vs. ragazz- $i$ m.pl; ragazz-a f.sg ragazz-e f.pl) - and displays both the French (PAs) and the Spanish (BNs) pattern. The choice between the two is considered optional (see Section 4). This predicts that in Italian a BN and a PA have exactly the same syntactic features and semantic import.

In this contribution, we expand the empirical perspective to Northern Italian Dialects (NIDs) and show that (i) the crosslinguistic correlation with number marking on $\mathrm{N}$ is indeed solid once only number marking on masculine is considered, but (ii) the optionality-based analysis of the varieties with both PAs and BNs cannot be maintained. In order to reconcile (i) and (ii) we argue that PAs and BNs are not semantically equivalent in languages that allow for both. PAs possess an additional feature with respect to BNs in these languages, which we tentatively identify with a choice function in the terms of Reinhard (1997).

In sections 2 and 3, we focus on the varieties which have either BNs or PAs, providing an overview of their distribution within NIDs and establishing a direct connection between the presence of number marking on the masculine and the possibility to licence BNs, thus modifying the empirical generalization found in the literature. In section 4, we present the data from Italian, which presents both BNs and PAs, and complement them with the data from another NID variety, Ligurian. In section 5, we develop analysis of this BN/PA alternation in terms of two different types of indefinites, complementing it in section 6 with a proposal regarding the crosslinguistic variation in the realization of these two functions and the licensing of BNs via number marking on $\mathrm{N}$.

\section{BNs vs. PAs, the view from Northern Italian Dialects}

Looking at the microvariation attested among Northern Italian Dialects (NIDs), we find indeed patterns similar to the ones we have outlined for Spanish and French. ${ }^{3}$ We observe

3 The dialectal data come from four different fieldwork sessions we carried out in Emilia, Friuli and Liguria from September 2018 to September 2020. We used two different techniques, a translation task administered in Italian and an elicited production task prompted by video description. In this contribution, we will only be concerned with the data coming from the translation task. For a complete overview, see Pinzin \& Poletto (accepted). 
that some NIDs only allow for PAs ("French-like"), while others only allow for BNs ("Spanish-like"). Within the first group we find Emilian varieties, while within the second group we find Friulian varieties.

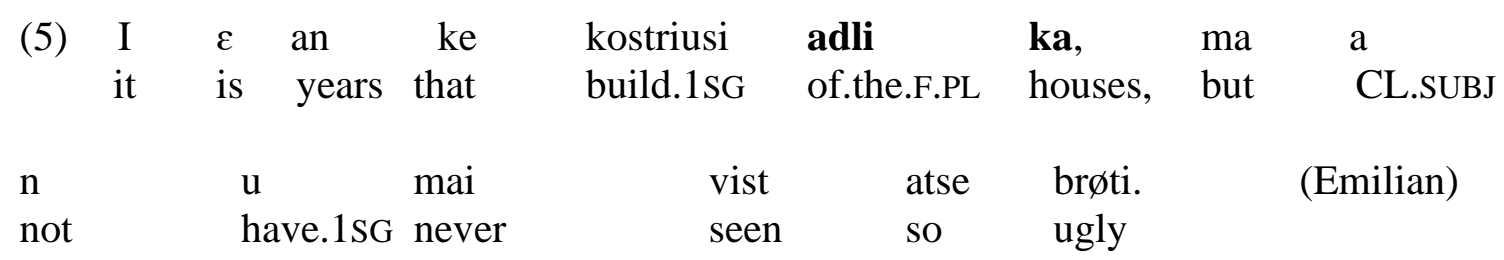

'I've been building houses for years, but I've never seen such ugly ones.'

$\begin{array}{llllllr}\text { (6) I } & \text { fa:s } & \text { cases di } & \text { kuant } \mathrm{k} & \mathrm{i} & \text { soi } & \text { nasu:t. } \\ \text { CL.SUBJ make.1SG } & \text { houses from when that } & \text { CL.SUBJ } & \text { am } & \text { born } \\ \text { 'I've been building houses since I was born.' } & \text { (Friulian) } & & \end{array}$

The following graphs show part of the results of the tasks we carried out in Emilia and Friuli. We select here only one of the tasks we carried out during our field work, namely the one that is relevant to show the point we want to make: a translation task from standard Italian into the dialectal variety was administered to the native speakers. The task contains 70 Italian input sentences plus 29 fillers and lasts around 40 minutes. The task is balanced for type of determiner (PA / BN / generic definite / nominal quantity / adjectival quantity / cardinal number), dislocation (right/left/no dislocation), polarity, gender, and number. We interviewed 7 speakers for Friulian (5 from the area around Gorizia and 2 from the area around Cordenons), 8 speakers for Emilian (from Dosolo, Villastrada di Dosolo and Viadana) and 3 speakers for Ligurian (from Arenzano). ${ }^{4}$ The input sentences have been orally presented by the researcher to the speakers, who were asked to translate them. For the inputs requiring it (e.g., left/right dislocations), we provided a brief oral context. Sometimes the speakers rejected the input or did not understand it in the given context, therefore, the total number of outputs produced is not always the same. ${ }^{5}$ All the translations have been recorded, transcribed, and transferred in CSV format. The data have then been tagged following the DiFuPaRo format (see https://difuparo.linguistik.uzh.ch/\#about for a description).

The graphs show the counts (on the y axis) of the different kinds of indefinites produced as a translation of an Italian input containing a BN, a PA, a definite article (on the $\mathrm{x}$ axis). The different columns identify different outputs, as highlighted in the legend ("quantity" groups together both adjectival quantities, e.g., Emil. tropa 'too much', and nominal ones, e.g., Friul. un pok 'a bit').

\footnotetext{
$4 \quad$ The data collection in Liguria has been hindered by the SARS-Covid19 pandemic. We are planning to collect other data as soon as the conditions are stable enough.

5 Note that this does not invalidate the results: the distribution of BN/PA/def inputs across the three different areas is comparable, no significant difference has been found crossing input type and variety $(\mathrm{Chi} 2=2.054, \mathrm{p}=0.726)$.
} 
Figure 1. Kinds of indefinites produced by Emilian speakers (questionnaire)

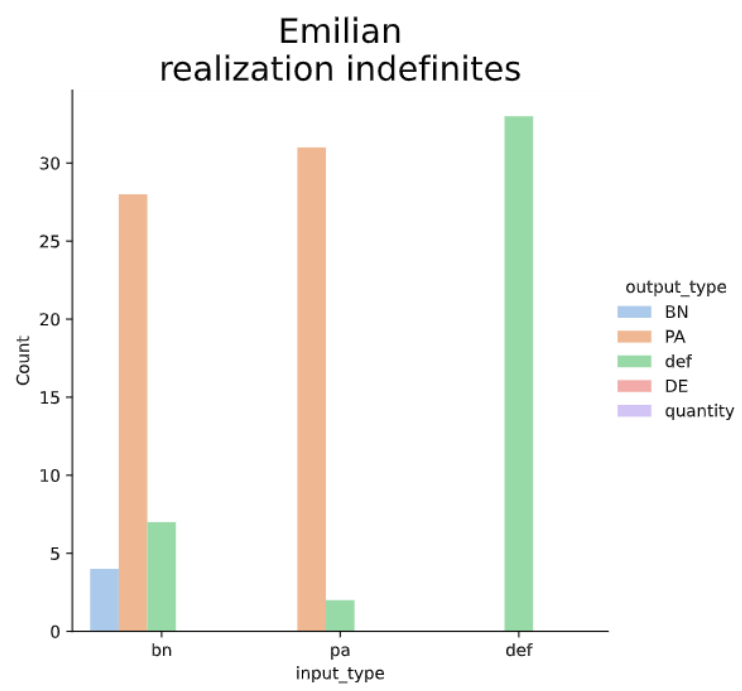

Figure 2. Kinds of indefinites produced by Friulian speakers (questionnaire)

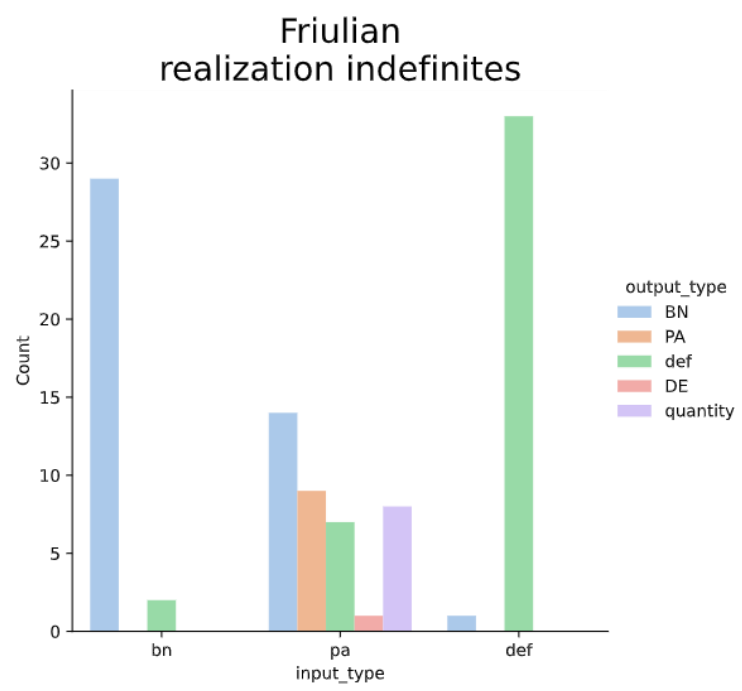

Emilian speakers (Figure 1) frequently produce PAs both with input PA and with input BN. BNs are not generally produced. Friulian speakers (Figure 2), on the other hand, frequently produce BNs both with an input BN and with an input PA. PAs, in this case, are not generally produced. The distribution of definite articles, finally, looks similar in both varieties. A $\chi^{2}$ test confirms that the distribution of the outputs in the two different varieties is significantly different $\left(\chi^{2}=69.772, \mathrm{p}=<0.001\right)$. A further pairwise comparison for output type, performed adjusting the significance threshold with the Bonferroni correction (significance $\leq 0.0167$ ), shows that, as visually observed, only the distribution of $\mathrm{BN}$ and PA outputs is significantly different among the two varieties (BNs: $\chi^{2}=47.101, \mathrm{p}=<0.001$, PAs: $\chi^{2}=46.448, \mathrm{p}=<0.001$ ), while the distribution of definite outputs is not $\left(\chi^{2}=0.211, \mathrm{p}=0.646\right)$. It is apparent from these data that Emilian speakers do not generally accept BNs, while Friulian speakers do not generally accept PAs. However, we also notice that in both varieties we have speakers who accept the less 
acceptable option. Interestingly, the speakers accepting the less acceptable option (i) do it only when that option is present in the input, (ii) are the youngest and, presumably, more interfered with Italian. This is visible in Figure 3, where BNs for Emilian and PAs for Friulian stand out as being produced by the youngest speakers (see Pinzin \& Poletto accepted for more details). ${ }^{6}$ We interpret this as the result of the crosslinguistic influence of Italian, prompted by the presence of a $\mathrm{BN}$ in the input sentence.

Figure 3. Mean age per output type

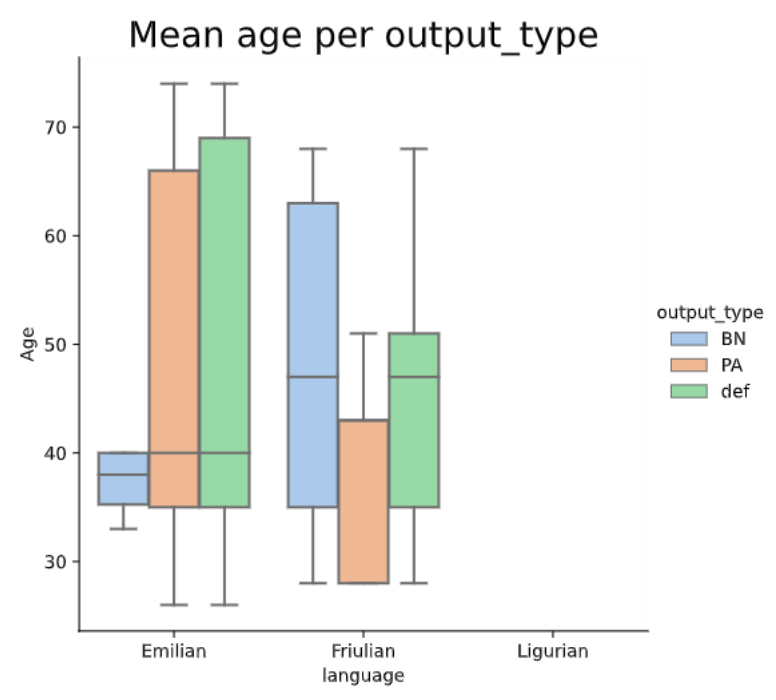

An evident asymmetry between Friulian and Emilian is the presence, in the former, of the additional possibility "quantity marker" as a translation of an input PA. A typical representative of this class is un pok/alk 'a bit'.

(7) $\mathrm{Ai}$

have.1SG

kuet un pok di pan. (Friulian, Chiopris)

'I baked some bread.' [Italian input: 'Ho cotto del pane']

This fact will be taken into consideration in Section 6, where we will show its relevance for setting a potential analysis for PAs in languages like Italian and Ligurian. As already shown, definite articles as translations of BN/PA inputs are consistently distribution among the two languages. ${ }^{7}$ Along the same lines, in both languages a definite article in the input leads to a translation with a definite article in almost all cases. We will see in Section 4 that the exact same distribution holds for a language like Ligurian, which displays yet a different pattern with respect to the distribution of BNs and PAs. The ASIt data collected in Pinzin \& Poletto (accepted) show that the same situation holds for the entire set of NIDs for which we have data: irrespective of the distribution of PAs and BNs, definite articles pop up with exactly same frequency in all varieties as a possible

6 The number of speakers who participated to the test is too low for a statistical analysis. The results, however, point to a pattern to be further investigated in the future.

$7 \quad$ With the input presenting the option preferred by the dialect (PAs for Emilian, BNs for Friulian), definite articles appear around 6-6.5\% of the time. With the input presenting the less preferred/ungrammatical option (BNs for Emilian, PAs for Friulian), definite articles appear around $17-18 \%$ of the time. 
minority alternative for introducing an indefinite object. In Pinzin and Poletto (Accepted) we conclude from these data that the distribution of the two types of indefinites in the language (PAs and BNs) is independent from the distribution of definite articles used in indefinite contexts, a conclusion we also adopt here. This second phenomenon can be better understood under the general label of Generic/Weak Definites (G/WDs, Carlson and Sussman 2005, Schwarz 2014, Aguilar-Guevara 2014, Corblin 2013) of the type illustrated in the following example (Italian):

$\begin{array}{lllll}\text { Lavo i } & \text { piatti da } & \text { solo } & \text { da } & \text { sempre, } \\ \text { wash.1sG the } & \text { dishes by } & \text { alone } & \text { since } & \text { always }\end{array}$

non ho bisogno della lavastoviglie!

not have.1SG need of.the.F.SG dishwasher

'I've always washed the dishes by myself, I don't need the dishwasher!'

The same use of the definite article is also attested in Italian, Spanish, French and not only in all the NIDs we checked, ${ }^{8}$ which shows that it is orthogonal to the problem we are dealing with here. We leave aside from our investigation these instances of weak definites and in this contribution we focus instead on the alternation between PAs and BNs.

\section{The role of morphology, number on $\mathbf{N}$}

As mentioned in the introduction, the difference between "French-like" and "Spanishlike" varieties with respect to the realization of indefinite objects has been related in the literature with the typology of gender and number marking on the noun $(\mathrm{N})$. This proposal has been supported both synchronically (Delfitto \& Schroter 1991, Stark 2016, Stark \& Gerards 2020, Gerards \& Starke 2020) and diachronically (Carlier 2007, Carlier \& Lamiroy 2014, Mathieu 2009).

Synchronically, French and Spanish differ with respect to the number of features overtly encoded on $\mathrm{N}$ by autonomous morphs. While Spanish marks plural number on $\mathrm{N}$ by means of a specific morph, $-s(9)$, French does not overtly mark plural number on $\mathrm{N}$, at least on regular nouns (11). ${ }^{9}$

la niñ-a (F.SG) vs. las niñ-a-s (F.PL)

(10) el niñ-o (M.SG) vs. los niñ-o-s (M.PL)

(11) la mezõ (F.SG) vs. le mezõ (F.PL)

(Spanish)

(French)

8 In some central varieties, the definite article seems to enter in the syntactic-semantic space of indefiniteness covered in the varieties we investigated by BNs/PAs (Cardinaletti \& Giusti 2018). We leave this issue for further investigations. For our varieties, the use of definite articles in indefinite contexts is to be ascribed to their use as G/WDs and never extend to cover any of the indefinite functions covered by either BNs or PAs.

9 There is a set of masculine Ns ending in /al/ which at the plural substitute /al/ with /o/, thus marking the alternation (e.g., /animal/ vs. /animo/). Other more marginal cases in which the $\mathrm{N}$ is marked for the number alternation are /bœf/ vs. /bø/. See Massot (2014) for a more detailed typology. Note that from now on we will use a simplified IPA for transcribing French, given the lack of consistency between orthography and pronunciation. 
lə garsõ (M.SG) vs. le garsõ (M.PL)

From the diachronic point of view, Carlier (2007), Carlier \& Lamiroy (2014), Mathieu (2009) underline that Old French used to have BNs in argumental position, much like Spanish today. The point in time in which this possibility was lost, and PAs become obligatory overlaps with the loss of the overt number marking on $\mathrm{N}$. These synchronic and diachronic observations led the scholars quoted above to formulate a correlation between absence of BNs and absence of overt morphs marking plural on $\mathrm{N}$, with the corollary idea that PAs come into play to fill-in for the place left open by BNs.

We have controlled for this correlation in NIDs, collecting the different types of number marking on $\mathrm{N}$ which are attested in the ASIt database. ${ }^{10}$ We have been able to identify the following Ns for which both a singular and a plural form are provided in the ASIt corpus: (masculine) ragazzo-ragazzi 'boy-boys', libro-libri 'book-books', amicoamici 'friend-friends', bambino-bambini 'kid-kids'; (feminine) ragazza-ragazze 'girlgirls', donna-donne 'woman-women', sorella-sorelle 'sister-sisters', (sta)sera-sere '(this)evening-evenings'. We took into consideration only regular markings, i.e., we took out of the equation those subclasses of Ns which show a class-specific or lemma-specific number marking (e.g., Fr. /animal/ vs. /animo/ or Friul. palatalized plurals, see Vanelli 2010). Our results only partially confirm those reported in the literature: we have found that absence of BNs only correlates with absence of plural marking on masculine Ns, the presence of plural marking on feminine Ns are irrelevant to the link with BNs. An example of this type of pattern is Emilian. We have seen above that this variety does not have BNs and that PAs are produced both with a BN and a PA Italian input. Notwithstanding, it has a robust number marking on feminine Ns, as confirmed both by the ASIt data and our fieldwork:

Emilian

(13) la pütel-a vs. li pütel-i / la surela vs. li sureli (Luzzara)

'the girl' vs. 'the girls' / 'the sister' vs. 'the sisters'

(14) la pütel-a vs. li pütel-i / la karta vs. li karti (Villastrada di Dosolo2)

'the girl' vs. 'the girls' / 'the paper' vs. 'the papers (game cards)'

However, Emilian varieties do not display any number marking on masculine Ns.

al pütlet vs. i pütlet / al lebar vs. i lebar

(Luzzara)

'the kid vs. the kids' / 'the book' vs. the books'

al pütlet vs. i pütlet / al nonu vs. i nonu (Villastrada di Dosolo1)

'the kid' vs. 'the kids' / 'the grandfather' vs. 'the grandfathers'

We can conclude that the relation between the absence of number marking and the absence of BNs only concerns masculine nouns and not feminine nouns. This data can be explained in two ways: (i) only number-syncretic masculine blocks BNs, (ii) one number-syncretic gender is enough for blocking BNs, whether it is masculine or feminine

10 This kind of testing involves a consistent number of varieties and is highly relevant for (dis)confirming and refining the correlation, which has only been argued for in relation to a handful of languages in the literature. 
does not matter. For now, we do not have clear evidence in favor of either hypothesis. ${ }^{11}$ Irrespective of this issue, a language such as Emilian showing plural marking only on feminine Ns counts as a language of the "French" type, in which BNs are absent and PAs obligatory. Therefore, our data from the NIDs further strengthen the correlation between number marking on $\mathrm{N}$ and the distribution of BNs and PAs.

\section{The issue posed by Italian-like varieties, optionality?}

Up until now, we only dealt with a dichotomic alternation between PAs and BNs and noticed that languages select one of the two options. We pointed out that there are languages which obligatorily insert PAs for realizing the least marked indefinite objects (French, Emilian) and languages which do not have PAs at all and only display BNs for realizing the least marked indefinite objects (Spanish, Friulian). The data on morphological number marking on $\mathrm{N}$ support this dichotomic opposition, since, prima facie, number can in principle either count as marked or unmarked on $\mathrm{N}$. We have also seen that there are languages where number marking is different depending on gender.

As shown above, Emilian is such a language: number is marked on feminine Ns and unmarked on masculine Ns. This problem, however, could be dealt with by assuming that the relevant parameter "number marked on N" can only be set to YES if both masculine and feminine are overtly marked. One might then argue that the relevant item for the lexicalization of the indefinite function is the number morph itself. This would give rise to a competition between number morphs and PAs for the lexicalization of the least marked indefinite function. If number marking is present, it can realize indefinites, if it is absent, PAs come into play and lexicalize that function instead ("PA pattern": French, Emilian). However, there are Romance languages for which this dichotomy is not suitable. Standard Italian, for example, is such a language, since it displays both BNs and PAs (see (3)-(4)). In our fieldwork, we identified another language in which both BNs and PAs are attested: Ligurian. ${ }^{1213}$

Ligurian

(17) E meestre an skritu letre tta a matina. (Arenzano)

the teachers have written letters all the morning

'The teachers wrote letters the whole morning.'

11 There are some varieties around Bormio (Alpine Lombard) which show a syncretism for number in the feminine paradigm but not in the masculine (la fém- $a$ vs. li fém- $a$, Livigno 2, ASIt). These varieties have BNs. This might be evidence in favor of the first option (only number syncretic masculine blocks BNs). However, before jumping to this conclusion, a more in-depth study of the distribution of this number syncretic forms is necessary.

12 During our fieldwork, we found a differentiation between two varieties of Ligurian, the speakers either follow the "Italian" pattern, allowing both for BNs and PAs, or the "FrenchEmilian" pattern, allowing only for PAs. In this section we clearly refer to the first type (see Pinzin $\&$ Poletto accepted).

13 The numbers we show are related to a subset of the speakers we interviewed. This is because we found a split between two varieties of Ligurian. The variety we are looking at in this context is the one which aligns with Italian with respect to the distribution of BNs and PAs. For further information see Pinzin \& Poletto (accepted). 

(18) A
mamà a $\quad 1$ à purtau dee kandeie. ( Arenzano)
the mother she
CL has brought of.the.F.PL candles
'Mom brought candles.'

Figure 3. kinds of indefinites produced by Friulian speakers (questionnaire)

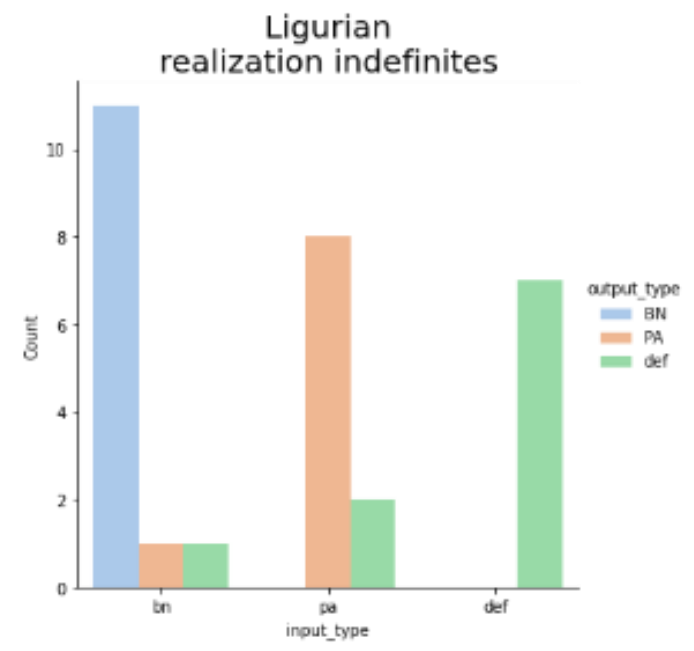

Ligurian speakers produce BNs when the input contains a BN and PAs when the input contains a PA. There seems to be no friction with the standard Italian input as it was the case with Emilian and Friulian. ${ }^{14}$ Notice that also in this case the speakers produce definite determiners as a minority pattern. The same conclusion we draw for Emilian and Friulian is therefore valid in this case too.

Languages as Ligurian and Italian clearly show that BNs and PAs do not appear as dichotomic alternatives along the line drawn by number marking on $\mathrm{N}$. A possible way to deal with these languages is to claim that they represent a case of optionality in the realization of the indefinite function which is instead consistently realized by PAs in French and Emilian and by BNs in Spanish and Friulian. Stark (2016) Stark \& Gerards (2020), Gerards \& Stark (2020), for example, put forth the idea that there is one single functional head either realized by Fr. $d e$, It. $d i$ 'of' (= PAs) or by overt number morphology $(=\mathrm{BNs})$. This functional head, labeled Individuation $\left(\mathrm{Ind}^{\circ}\right)$ and necessary to derive nominal arguments, hosts number (NUM) features. According to the Authors, Ind $^{\circ}$ is realized in Spanish either by the plural morph /s/ or by absence of marking, so that BNs are consistently derived. Instead in French, which lacks overt number morphs, Ind $^{\circ}$ is

14 Ligurian also has the additional possibility to translate indefinites with the bare preposition de 'of'. However, this possibility is restricted to negative contexts (see Battye 1990, Garzonio \& Poletto 2020 for an in-depth discussion). We let aside this fact because there is no direct correlation between having the possibility of using bare DE under negation in indefinite contexts and the distribution of BNs and PAs at the positive. Valtellina speakers (as Bormio/Livigno) use BNs at the positive and bare DE at the negative. French speakers use PAs at the positive and are DE at the negative. Emilian speakers use PAs both at the positive and at the negative. 
always realized by $d e$ 'of', so that PAs are consistently derived. ${ }^{15}$ The issue posed by Italian is addressed in terms of optionality, translated as optional movement of $\mathrm{N}$ to Ind $^{\circ}$ (Pesetsky \& Torrego 2007). ${ }^{16}$ This account predicts that the same functional structure (= same sequence of syntactic-semantic functions) can be realized alternatively with PAs or BNs in Italian and Ligurian, so that there should not be any detectable semantic distinction between the two.

In the remainder of contribution, we will show that an analysis in terms of optionality is not adequate to capture the distribution of PAs and BNs in the Italian and Ligurian type of languages, whose data are better accounted for by splitting the single function for indefinites in two.

\section{Splitting indefinites}

In Italian and Ligurian the interpretation of Bare Nouns and indefinite Partitive Articles does not overlap. This means that the BN in (19a) and the PA in (19b) realize two different sets of syntactic-semantic features.

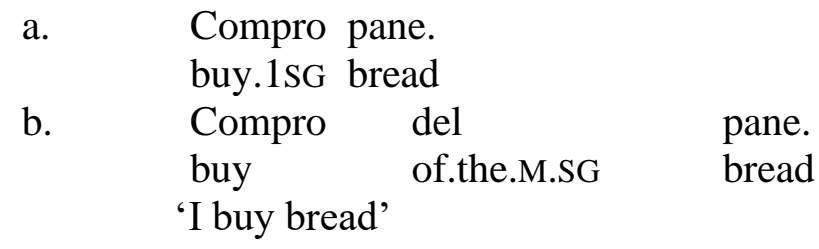

This intuition is shared by Cardinaletti \& Giusti (2018). In their analysis of the different Italian varieties adopting these two kinds of indefinites, they recognize the fact that the two - when both present in the variety - do not overlap. When there are different choices for the realization of indefinites, one carries the unmarked semantics (defined as "narrow-scope") while the others carry more marked flavors (PAs are defined as carrying

15 Note that an additional lowering mechanism at Morphological Structure is needed to have the agreement morphs on $d e$. These details of the proposal are not relevant for the present argumentation.

This optionality is connected by the Authors to the different status of the gender and number marking morphs in the language. Morphologically speaking, the traditional analysis takes the regular morphs marking number in Italian (/i/ and /e/) to be portmanteaus for both gender and number (Alexiadou 2004 but see Passino 2009 for a different perspective).

i. il libr-o vs. i libr-i la scatol-a vs. le scatol-e

(Italian)

'the book' vs. 'the books' (M) 'the box' vs. 'the boxes' (F)

This pattern is different both from the one we see in Spanish, where there is a single numbermarking morph for masculine and feminine (/s/), and from the one we see in French, where there is no regular marking on $\mathrm{N}$ (see (5)). Following the adopted morphosyntactic model, the claim is that in Italian [NUM] is realized lower on $\mathrm{N}$ and is subsequently probed by a higher instantiation of that feature on Ind ${ }^{\circ}$ (downward agree). This probing mechanism leads to an optional movement of $\mathrm{N}$ to $\mathrm{Ind}^{\circ}$. In case the movement option is chosen, the final form will be a BN, if it is not, the same mechanism that we saw in French is applied and $d i$ 'of' is inserted (PA). 
a "small quantity" flavor). We think that this intuition is correct and intend to go one step further, and single out the property that distinguishes between BNs and PAs. The crosslinguistic differences we observe in Romance are due to the fact that the languages make different choices with respect to the way they lexicalize this feature.

The first argument against the idea that there is pure optionality between BNs and PAs in languages like Italian comes from the fact that there are contexts in which only PAs are available, while BNs are not.

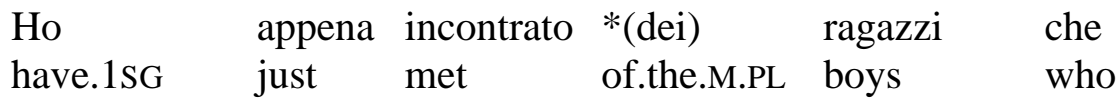

$\begin{array}{llll}\text { mi } & \text { avevi } & \text { presentato } & \text { ieri. } \\ \text { me.DAT } & \text { had } & \text { introduced } & \text { yesterday }\end{array}$

'I just met some boys you introduced me yesterday'

In the example in (20) the indefinite is modified by a restrictive relative clause and is specific. In this case only PAs are acceptable, while BNs are not. The sentence refers to an event in which the speaker meets an indefinite number of specific boys, the ones identified by the restrictive relative clause. The fact that PAs can be interpreted as specific and BNs cannot is already established in the literature (Cardinaletti \& Giusti 2016 a.o.). This fact, however, is still compatible with an optionality approach, for which it is enough to prove that BNs are available in a subset of the contexts in which PAs are available. This would make BNs and PAs still "optional" competitors, but only for a subset of the possible interpretations that PAs have. This hypothesis, however, struggles with sentences in which only BNs and not PAs are available:

$\begin{array}{lllllll}\text { Costruisco } & \text { \#delle) } & \text { case } & \text { da } & \text { quando } & \text { sono nato. } & \text { (Italian) } \\ \text { build.1sG of.the.F.PL houses } & \text { since } & \text { when } & \text { am born } & \end{array}$
'I've built houses since I was born.'

We descriptively label this type of contexts as "long term activities". In (21) PAs are not adequate and only BNs can appear. The presence of a PA in this sentence leads to a different but infelicitous interpretation in which the speaker is asserting that he is building a set of houses since he was born. Ligurian, which has both PAs and BNs as Italian, shows the same contrast, with the following sentence deemed as infelicitous:

\#Kustruifu dee $\quad \mathrm{k} \varepsilon \quad \mathrm{da}$ kwando so nafyu. build.1SG of.the.F.PL houses from when am born 'I've been building houses since I was born.' (Ligurian, Arenzano)

As expected, Emilian and French remain consistent and always select PAs also for the intended meaning 'I perform the activity of building houses since...':

$\begin{array}{lllll}\text { Je } & \text { construis des } & \text { maisons } & \text { depuis } 30 & \text { ans. (French) } \\ \text { I } & \text { build.1SG of.the.F.PL houses } & \text { from } 30 & \text { years }\end{array}$


I $\varepsilon$ an ke kostruisi adli ka. (Emilian, Dosolo)

it is years that build.1SG of.the.F.PL houses

'I've been building houses for years.'

We believe that these observations, which prove that $\mathrm{BN}$ can occur in domains where PAs are not admitted and vice versa, militate against an analysis in terms of optionality for the PA/BN alternation in Italian and Ligurian and support a split between two kinds of indefinites.

The next question to be answered is evidently: what is the feature that discriminates between BNs and PAs? The first two potential candidates that come to mind are specificity and speaker-oriented existence. We have already seen that PAs can be specific while BNs cannot (as shown in (20)). If specificity were the discriminating feature, ${ }^{17}$ then we would expect a 1-to-1 mapping between PAs occurring only in specific contexts and BNs in non-specific ones. However, this is not the case: while it is true that BNs cannot be specific, PAs can be both specific, as shown in (20) and non-specific in the following example.

$$
\begin{aligned}
& \text { Mangia del pane ogni giorno. (Italian) } \\
& \text { eats of.the.M.PL bread every day } \\
& \text { 'She eats bread every day' }
\end{aligned}
$$

The sentence denotes an event of eating an indefinite quantity of bread (del pane), repeated every day. The most salient interpretation involves a different indefinite quantity of bread every day. This interpretation requires the DP del pane to be non-specific. Hence, assuming specificity to be the feature distinguishing between BNs and PAs would take us back to optionality, at least in a subset of contexts. Given this, we rule out specificity as the relevant feature discriminating BNs from PAs.

A second possibility is to consider the notion of speaker-oriented existence, i.e., the speaker's intention to refer to something/one whose existence she asserts/believes in. Matthewson (1998) proposes that St'át'imcets (a Salishan language spoken in British Columbia) overtly encodes assertion of existence in its nominal system. In the same vein, Gambarage (2019) proposes a similar approach to nominals in Nata (a Bantu language spoken in Tanzania). In this language, a nominal argument may come with a prenominal augment (o=ro-síri) or without it (ro-síri).

(26) (Nata)

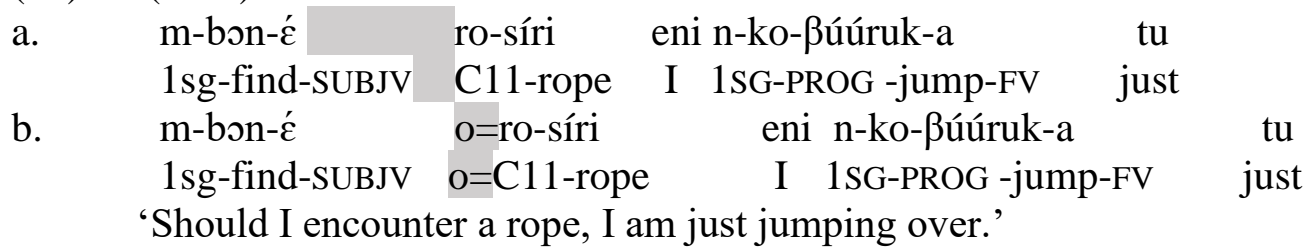

(Gambarage 2019:170-171)

17 See von Heusinger (2019) for a review of the different definitions of specificity. Committing to one or the other is not relevant for our argumentation since the sentence in (27) would be considered as non-specific by any of them. 
The distribution of these two forms depends on the speaker's beliefs regarding the existence of the denoted element. If the speaker is talking about a rope she believes is there (e.g., the rope of a hurdle in a specific competition), (26)b is felicitous; if, on the other hand, the speaker is talking about possible ropes whose existence she is not committed to, (26)a is felicitous. These data are interesting especially because of the relation with specificity. Unaugmented nominals cannot be specific, while augmented ones can be both specific and non-specific (Gambarage 2019: 193-194). This indicates a presuppositional relationship between specificity and belief of existence, in that specificity presupposes belief of existence. We have already seen that, in a parallel way, in Italian BNs cannot be specific, while PAs can be both specific and non-specific. Can we then claim that belief of existence is the discriminating feature between BNs and PAs in Italian too? The data speak against such an option. If this were the case, we would expect an exact parallel between the distribution of PAs-BNs and augmentedunaugmented nominals. The typical contexts licensing unaugmented nominals presented by Gambarage are non-factual, as the conditional in (26) (but also negation, polar questions etc.). In these contexts, as we have seen, unaugmented nominals convey lack of belief of existence, augmented nominals belief of existence. However, this does not match the distribution of PAs and BNs, which is not set by the speaker's beliefs regarding the existence of the nominal. The following polar question containing a PA is perfectly natural both in a context in which the speaker thinks that there are hurdles or not.

$$
\begin{aligned}
& \text { Se incontrerò degli } \quad \text { ostacoli, li salterò. (Italian) } \\
& \text { if meet.1SG.FUT of.the.M.PL hurdles them jump.FUT.1SG } \\
& \text { 'If I encounter any hurdles, I'll jump over them' }
\end{aligned}
$$

We conclude that speaker's beliefs of existence, as much as specificity, cannot be the feature we are looking for. Consider a sentence like (21) containing a BN. Here, belief of existence does not seem to be relevant at all: it is impossible to judge if the speaker believes or not in the existence of case 'houses', since the 'housebuilding' event is not anchored to any specific spatiotemporal coordinate. Actually, it is generic (i.e., the event is bound by a generality operator, Delfitto 2005, Longobardi 2001). Notice furthermore that lack of belief of existence for BNs is not connected to a generic reading of the event.

Let us take the following sentence:

$$
\begin{aligned}
& \text { Se costruisci case, chiamami. (Italian) } \\
& \text { if build.2SG houses call.me } \\
& \text { 'If you build houses, call me.' }
\end{aligned}
$$

The most salient interpretation of this sentence is "if you identify yourself as someone who potentially builds houses, call me". This is, again, a generic interpretation, in which there is no need for an actual event of building houses to happen in order to trigger the "if statement". Since no actualization is implied, any belief of existence with respect to the houses is irrelevant. There is, however, a second and less prominent possible interpretation of (28), which takes the actualization of the house-building event to be relevant for triggering the "if statement": "if you happen to be in a "housebuilding' event, call me". This interpretation is natural in a context in which, for example, the sentence is produced by an official of the municipal real-estate register, to which any new building has to be communicated. In this case, the actualization of the building event is needed for 
the calling to happen (i.e., the speaker does not expect every person capable of building houses to call her at any given moment, she expects a call only when there is an actual event of building houses). The difference between the two interpretations is related to the anchoring of the 'housebuilding' event, which can be either bound by a generality operator or linked to the spatiotemporal coordinates of the addressee ("if you build houses in general" vs. "if you are building houses when you receive this message"). The relevant fact is that also in the second case there is no belief regarding the existence or not of the houses as far as the speaker is concerned. ${ }^{18}$

Let us then compare the same sentence with a PA.

$$
\begin{aligned}
& \text { Se costruisci delle case, chiamami. (Italian) } \\
& \text { if build.2SG of.the.F.PL houses call.me } \\
& \text { 'If you build houses, call me.' }
\end{aligned}
$$

In this case, the most salient interpretation is the one in which there is an anchoring of the event to the spatiotemporal coordinates of the addressee, i.e., the "if statement" is triggered only in case there is an actual event of building houses. The second option, the one in which the calling event is triggered by the addressee being someone who potentially builds houses, is still available but less prominent. ${ }^{19}$ These facts imply that the feature differentiating PAs from BNs in Italian (and Ligurian) has to have the following properties: (i) It triggers these different interpretational preferences, (ii) but it still maintains the spectrum of interpretational possibilities, (iii) it must be a prerequisite of belief of existence and specificity, since we have seen that we have the same asymmetry in both cases: BNs are blocked from having access to these interpretations while PAs can have both.

We propose to identify the relevant feature using the notion of Choice Function (CH(f), see Reinhart 1997), i.e. a function that applies to a set and has its output a member of that set. The following structure exemplifies the basic idea behind our approach. BNs are characterized by a set of functions corresponding to syntactic functional projections adding values to the nominal root. We will summarize it with the shortcut FNP (corresponding to the functional layer of the NP). Such functions include, for example, gender and number specifications. On top of these functions, it is possible to merge an additional layer corresponding to the Choice Function, which takes as an input the semantics of the FNP and modifies it. Italian and Ligurian lexicalize the structure with the $\mathrm{CH}(\mathrm{f})$ with PAs, while the structure without it with BNs.

18 The two readings ("existential" and "generic") are therefore due to two different readings of the whole event and not to the characteristics of the $\mathrm{BN}$ itself, which remains the same indefinite in both cases (Longobardi 2001). The only way to directly encode genericity in the nominal structure in Romance is by adding a definite determiner: * $(i)$ dodo sono estinti 'dodos are extinct'.

19 This reading becomes more prominent when we add an adjectival modifier as belle 'beautiful'.

i. Se costruisci delle case belle, chiamami. (Italian)

if build.2SG of.the.F.PL houses beautiful.F.PL call.me

'If you build beautiful houses, call me.'

We let aside the issue of nominal modification and leave it for further research. 


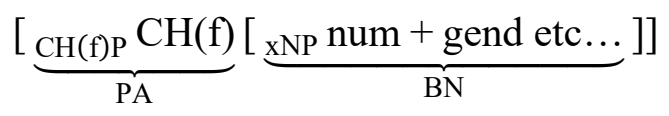

Let us see more in detail how this works. We have already seen that both BN and PA arguments are indefinites (see also Longobardi 2001). With Dobrovie-Sorin \& Beyssade (2004) and Ihsane (2008), we take BNs to denote properties, i.e., the extension of the nominal, the set of objects labelable as such. If pluralized, they correspond to the power set of that set. ${ }^{20}$ Case 'houses' denotes the power set of the set of objects we could label as casa, a set of sets. When a predicate takes the BN case 'houses' as its argument, the predicate takes any random member of the set to be a possible argument. The final interpretation of the predicate ("existential" vs. "generic") depends on its binding to some specific spatiotemporal coordinates / to a generality operator and not on the semantics of the $\mathrm{BN}$ indefinite argument. We propose that PAs (in Italian and Ligurian) are distinguished from $\mathrm{BNs}$ by the addition of a $\mathrm{CH}(\mathrm{f}) \mathrm{P}$ merged within the functional space of the nominal structure. This function indicates the presence of a choice among the sets.

This choice is not restricted by any of the characteristics of the members of the set, any set in the denotation of the $\mathrm{BN}$ is adequate. Note that this does not actualize a specific choice on a member of the set, it only introduces a function for a choice. This function is actualized when a predicate takes the "PA nominal" as an argument. The denotation of BNs and PAs is then very similar: the $\mathrm{CH}(\mathrm{f})$ does not discard any part of the $\mathrm{BN}$ denotation. The only difference is that with PAs we define a function within the nominal itself that maps to a member of the set, activated for each event denoted by the predicate. This is what makes (21) awkward in Italian: the $\mathrm{CH}(\mathrm{f})$ requires activating the choice of a member of the set case 'houses' for the single building event going on since the speaker was born. This results in a reading in which there is a single indefinite set of houses which is under construction since the speaker was born, a rather peculiar situation. The same sentence with a BN, on the other hand, is not problematic. This is because no choice within the set case 'houses' is activated, and the event of building is not bound to a member of the set.

The relationship between the PA/BN distinction and specificity/belief of existence can also be motivated following this approach, since the presence of a $\mathrm{CH}(\mathrm{f})$ is a condition needed in order to further manipulate nominal reference. The choice function is a necessary prerequisite for merging other referential features within the nominal spine, as the ones instantiating speaker's belief of existence and specificity: only when a potential choice is initialized within the nominal, a subsequent further specification on that choice can be operated within the nominal itself. Adopting an approach along the lines of Ihsane

20 The pluralization operation can also be implemented using mereology (closure under sum formation, Link 1983) instead of set-theory. In addition, it can in principle both keep the singularities (inclusive, Sauerland et Al 2005 a.o,) or not (exclusive, Grimm 2013 a.o.). As far as we can see, both choices are orthogonal to our argumentation. Another relevant issue is the relationship between pluralization and the count-mass distinction, which has been claimed to be direct by some literature (Borer 2005 a.o.): nouns are born mass and turned into count by pluralization itself. While such an approach is well suited to explain the fact that many Ns can alternate between mass and count (e.g., coffee), it struggles to encode the clear preferences for one or the other that many others have (e.g., child). For reasons of space and scope of the paper, we will not address this issue here. We nonetheless underline that other approaches are plausible, in which the mass-count distinction is not a property of the noun but of the mereotopology of the objects within its extension (e.g., Wagiel 2018). 
(2008), we could claim that the quantificational and referential features are encoded higher in the spine of the nominal and the choice function is the key to open up that field; without the initialization of a potential choice, no specification on the choice can be added. $^{21}$

\section{Crosslinguistic variation and number marking on $\mathbf{N}$}

In this section, we take into consideration the generalization regarding number marking on $\mathrm{N}$ and the distribution of the realization of indefinite arguments as BNs/PAs. The generalization does not hold in the simple version presented in the introduction: it is not true that absence of number marking on $\mathrm{N}$ leads to the necessity of using PAs, while the presence of number marking on $\mathrm{N}$ leads to the presence of BNs. There are languages like Italian and Ligurian in which number marking on $\mathrm{N}$ is present, as well as both BNs and PAs. If our analysis is on the right track, a solution for these cases in terms of optionality between BNs and PAs makes the wrong predictions regarding the distribution of these forms, while splitting indefinites, possibly along the lines of what we defined as Choice function, provides us with a better coverage of the data. We will show that only by abandoning the idea that there is a single indefinite function for PAs and BNs can we provide a fairly straightforward account for the connection between number marking on $\mathrm{N}$ and the realization of indefinite arguments as BNs/PAs.

The formulation "the language $\mathrm{x}$ has BNs" descriptively means that the language $\mathrm{x}$ has the possibility of using nouns in argumental position without any (overt) prenominal element. In the languages we are dealing with, this possibility is restricted to indefinite arguments (mass singular and count plural) and to those varieties showing overt number marking on $\mathrm{N}$ in both genders. The presence of number marking only on one gender (feminine) is not enough, as the Emilian data show. Following part of the literature (Delfitto \& Schroter 1991, Stark 2016 a.o.), we connect this fact to the properties of the morphs marking number on $\mathrm{N}$ in these languages. These morphs, if present, lexicalize the part of the functional sequence of the nominal which makes the $\mathrm{N}$ suitable as an indefinite argument. If these morphs are completely absent, PAs will replace them and lexicalize these functions. This is what happens in French and Emilian, where we find PAs all over the place introducing indefinite arguments. These languages, therefore, flatten the opposition between the least marked kind of indefinites and the one characterized by the $\mathrm{CH}(\mathrm{f})$, both are syncretically realized with the insertion of PAs. If these morphs are present, on the other hand, we have two possibilities, either they lexicalize just the lower function and leave the higher one for PAs, or they go all the way and lexicalize both functions. If the language has the first kind of number morphs, we observe an overt opposition between the two kinds of indefinites (as it is the case in Italian and Ligurian).

If the language has the second kind of number morphs, we will see no overt opposition between the two kinds of indefinites, both realized as "BNs" (Spanish and Friulian).

$21 \quad$ Note that this approach is not compatible with the idea that $\mathrm{CH}(\mathrm{f})$ can be bound from any possible position within the sentence. The different scope properties are connected to the presence/absence of additional features along the nominal spine. 


\begin{tabular}{c|c|c|}
\multicolumn{1}{c}{} & \multicolumn{1}{c}{$\boldsymbol{C N}$} & $\boldsymbol{C h F P}$ \\
\cline { 2 - 3 } Fr./Em. & PA & PA \\
\cline { 2 - 3 } It./Lig & number morphs & PA \\
\cline { 2 - 3 } Sp./Friul. & number morphs & number morphs \\
\cline { 2 - 3 } & &
\end{tabular}

If Friulian and Emilian are two faces of the same coin - i.e., both languages realize syncretically the two kinds of indefinites we identified - we expect to find the same pattern with respect to the translation of the Italian inputs. In both languages we expect input PAs and input BNs to be translated in the same way, either as PAs (Emilian) or as BNs (Friulian). The data for Emilian confirm this expectation. ${ }^{22}$ In Friulian, however, we find another pattern: while it is true that BNs are always translated with BNs, PAs can be equally translated with BNs or by means of other quantity markers. ${ }^{23} \mathrm{We}$ propose to analyze this as an effect of the type of test used, i.e., a translation task, and the bilingual situation of the speakers. The test consists in the translation of a set of randomly distributed Italian sentences containing BNs, PAs and other indefinite nominals in object position. Coherently with their native Italian competence, Friulian speakers recognize the semantic difference between PA and BN inputs. Given that the test contains many sentences contrasting BNs and PAs, when translating a PA input (highlighted in red below), they try to replicate the opposition they perceive in Italian by recruiting other elements from their Friulian lexicon specialized for a slightly different indefinite semantics (let us call it quantP), which is however closer to the semantics of Italian PAs $(C h F P)$ than to the one of BNs $(F N P)$. In this way, they reconstruct the opposition they perceive in the Italian input and convey a similar indefinite semantics. Emilian speakers, on the other hand, do not have the same possibility. While they have the same problem (the input provides them with a differentiation they cannot overtly convey in their variety), they do not have a viable solution. There is nothing on the indefinite scale that is closer to the BN semantics than PAs, since the BN semantics is at the bottom of the scale. $^{24}$

FNP

Friul.

Em.

\begin{tabular}{|c|}
\hline number morphs \\
\hline PA
\end{tabular}

ChFP

\begin{tabular}{|c|c|}
\hline number morphs & quantity marker \\
\hline PA & quantity marker \\
\hline
\end{tabular}

If these considerations are on the right track, this asymmetric behavior gives us additional evidence for modeling the realization of indefinites as a scale in a containment relationship and not as a single functional projection (call it $\mathrm{D}^{\circ}$ ) with multiple possible feature specifications.

22 As already remarked, we interpret the marginal presence of BNs as a priming effect of the Italian input on the speakers which are more balanced/unbalanced towards Italian (young and working outside the community).

23 There are no correlations with test items or individual speakers, BN vs. quantity marker translations are randomly distributed. In many cases the speaker gave us both options.

$24 \quad$ One may wonder why they do not do as Friulians and translate PA inputs with quantity markers. The issue here is the fact that the Italian PA input does not conflict with the variety and therefore the speakers always go for the PA translation. The disambiguation mechanism can only apply where the variety does not have a direct translation of the input (BNs for Emilians and PAs for Friulians), forcing the speaker to perform a choice. 


\section{Conclusion}

In this work we have considered two phenomena related to indefinites in Romance: first, we have shown on the basis of dialectal data that the simple connection which links the presence of morphological number to the presence of BNs needs to further be qualified so that number must be present in the whole system, as it is the case in Friulian and not only in a subset of cases, as for instance feminine, as shown by Emilian data. Second, we have shown that in languages where there is morphological number but at the same time both BNs and PAs are possible, they do not entirely overlap. We have identified contexts in which only PAs are possible and contexts where only BN are possible, thus making an optionality account, even a partial one, untenable. In order to explain the distribution of PAs and BNs in standard Italian and Ligurian, we have proposed that the distinction between PAs and BNs is related to a single syntactic projection located on top of the functional layer internal to the DP that realizes a choice function (in the terms of Reinhard 1997), and not specificity or belief of existence, which imply the Choice function but have additional properties. We have argued that PAs realize ChFP, BNs do not. There is a lot that remains to be done, for instance to determine the exact relation between ChFP and specificity and belief of existence. It also remains to be understood what really happens in all those contexts in which both PAs and BNs are possible, where we expect an interpretive distinction, once empirical tests that are refined enough to detect the difference are developed.

\section{Acknowledgments}

First, we want to thank the DFG (PO 1642/81; Projeknummer 361314741) and by the SNSF (100012L_172751), whose support has been vital for carrying on the project in which this contribution has been developed. We also deeply thank all the people who contributed with their comments and observations to the refinement of the contribution: the collaborators of the project - Elisabeth Stark, Tabea Ihsane, Jan Davatz and Tania Paciaroni -, the participant to the PARTE initiative (http://www.parte.humanities.uva.nl/) - Petra Sleeman, Elvira Glaser, Giuliana Giusti, Silvia Luraghi, Anne Tamm, David Paul Gerards, Ilja Seržant, Thomas Stroebel, Ilmari Ivaska, and all the other people we met at conferences and seminars, as Maria Rita Manzini, Leonardo Savoia, Natascha Pomino, Pavel Caha, Carmen Sorin and many others. Finally, we deeply thank the linguistic collaborators who helped us in the data collection, their knowledge has been of utmost importance for the data and the analysis.

Francesco Pinzin takes responsibility for Sections 2, 3, 4, 5, and 6, Cecilia Poletto for Sections 1 and 7.

\section{References}

Aguilar-Guevara, Ana. 2014. Weak definites, semantics, lexicon and pragmatics. Utrecht: Landelijke Onderzoekschool Taalwetenschap. 
Alexiadou, Artemis. 2004. Inflection class, gender and DP internal structure. In G. Müller, L. Gunkel and G. Zifonun (eds), Exploration in Nominal Inflection, 2150. Berlin: Mouton de Gruyter. https://doi.org/10.1515/9783110197501.21

Battye Adrian. C. 1990. La quantificazione nominale, il veneto e l'italiano a confronto con il genovese e il francese. Annali di Ca Foscari 29: 27-44.

Beyssade, Claire. 2011. Bare Nouns in Predicate Position in French. In S. Pogodalla, M. Quatrini, C. Retoré (eds), Logic and Grammar: Essays Dedicated to Alain Lecomte on the Occasion of His 60th Birthday, 1-16. Berlin: Springer. https://doi.org/10.1007/978-3-642-21490-5

Borer, Hagit. 2005. Structuring Sense (vol. 1): In Name Only. Oxford: Oxford University Press. $\quad$ https://doi.org/10.1093/acprof:oso/9780199263905.001.0001

Cardinaletti, Anna and Giuliana Giusti. 2016. The syntax of the Italian indefinite determiner dei. Lingua 181: 58-80. https://doi.org/10.1016/j.lingua.2016.05.001

Cardinaletti, Anna and Giuliana Giusti. 2018. Indefinite determiners, variation and optionality in Italo-Romance. In R. D'Alessandro and D. Pescarini (eds.), Advances in Italian Dialectology, 135-161. Leiden/Boston: Brill. https://doi.org/10.1163/9789004354395_008

Carlier, Anne. 2007. From Preposition to Article: The Grammaticalization of the French Partitive. Studies in Language 31(1): 1-49. https://doi.org/10.1075/sl.31.1.02car

Carlier, Anne. and Béatrice Lamiroix. 2014. The grammaticalization of the prepositional partitive in Romance. In S. Luraghi and T. Huumo (eds.), Partitive Case and Related Categories, 477-522. Berlin: De Gruyter Mouton. https://doi.org/10.1515/9783110346060.477

Carlson, Gregory, and Rachel Sussman. 2005. Seemingly indefinite definites. In S. Kepser and M. Reis (eds.), Linguistic evidence: Empirical, theoretical, and computational perspectives, 71-85. Berlin: De Gruyter Mouton https://doi.org/10.1515/9783110197549.71

Chierchia, Gennaro 1997. Partitives, Reference to Kinds and Semantic Variation. In A. Lawson (ed.), Proceedings of Semantics and Linguistic Theory VII, 73-98. Ithaca, NY: CLC Publications. https://doi.org/10.3765/salt.v7i0.2792

Corblin, Francis. 2013. Weak definites as bound relational definites. Recherches linguistiques de Vincennes 42: 91-122. https://doi.org/10.4000/rlv.2184

Delfitto, Denis. 2005. Bare Plurals. In H. van Riemsdijk and M. Everaert (eds.), An Encyclopedia of Syntactic Case Studies, NIAS, Wassenaar.

Delfitto, Denis and Jan Schroter. 1991. Bare Plurals and the number affix in DP. Probus 3: 155-185. https://doi.org/10.1515/prbs.1991.3.2.155 
Dobrovie-Sorin, Carmen and Claire Beyssade. 2004. Définir les indéfinis. Paris: CNRS Editions. https://doi.org/10.1017/s0008413100004357

Gambarage, Joash Johannes. 2019. Belief of Existence Determiners: Evidence from the Syntax and Semantics of Nata Augments. Ph.D. thesis, University of British Columbia.

Garzonio, Jacopo and Cecilia Poletto. 2020. Partitive objects in negative contexts in Northern Italian dialects. Linguistics 58: 621-650. https://doi.org/10.1515/ling2020-0079

Gerards, David and Elisabeth Stark. 2020. Why Partitive Articles Do Not Exist in (Old) Spanish. In T. Ihsane (ed.), Bare Nouns vs. 'Partitive Articles': Disentangling Functions, 105-139. Leiden/Boston: Brill. https://doi.org/10.1163/9789004437500_005

Grimm, Scott. 2013. Plurality is distinct from number neutrality. In L. Fainleib, N. LaCara, and Y. Park (eds.), Proceedings of the 41 st Annual Meeting of the North East Linguistic Society, 247-258. Amherst: University of Massachusetts.

von Heusinger, Klaus. 2019. Indefiniteness and Specificity. In J. Gundel and B. Abbott (eds.), The Oxford Handbook of Reference. Oxford: Oxford University Press. https://doi.org/10.1093/oxfordhb/9780199687305.013.9

Ihsane, Tabea. 2008. The Layered DP: Form and meaning of French indefinites. Amsterdam: John Banjamins. https://doi.org/10.1075/la.124

Link, Godehard. 1983. The logical analysis of plurals and mass terms: A lattice theoretical approach. In R. Bäuerle, C. Schwarze and A. von Stechov (eds.), Meaning, use, and interpretation of language, 302-323. Berlin: de Gruyter. https://doi.org/10.1515/9783110852820.302

Longobardi, Giuseppe. 2001. How comparative is semantics? A unified parametric theory of bare nouns and proper names. Natural Language Semantics 9 (4): 335-369. https://doi.org/10.1023/A:1014861111123

Massot, Benjamin. 2014. De la fumée sans feu. Le -s graphique de pluriel des noms français : ni un s, ni un pluriel!. SHS Web of Conferences 8, 4e Congrès Mondial de Linguistique Française: 1837-1861. https://doi.org/10.1051/shsconf/20140801369

Mathieu, Eric. 2009. From Local Blocking to Cyclic AGREE. The Role and Meaning of Determiners in the History of French. In J. Ghomeshi, I. P. and M. Wiltschko (eds.) Determiners. Universals and Variation, 124-157. Amsterdam, Philadelphia: John Benjamins. https://doi.org/10.1017/s0022226711000065 
Matthewson, Lisa. 1998. Determiner Systems and Quantificational Strategies: Evidence from Salish. The Hague: Holland Academic Graphics. https://doi.org/10.14288/1.0087844

Passino, Diana. 2009. An element-based analysis of Italian inflection. In F. Montermini, G Boyé and J. Tseng (eds.), Selected Proceedings of the 6th Décembrettes : Morphology in Bordeaux, 63-75. Somerville:Cascadilla Proceedings Project.

Pesetsky, David and Ester Torrego. 2007. The Syntax of Valuation and the Interpretability of Features. In S. Karimi, V. Samiian, and W. K. Wilkins (eds.), Phrasal and Clausal Architecture, 262-294. Amsterdam: John Benjamins. https://doi.org/10.1075/la.101.14pes

Pinzin, Francesco and Cecilia Poletto. accepted. Indefinite objects in micro-variation. A cross-linguistic analysis of the distribution of Partitives Articles, Bare Nominals and definite determiners in Northern Italy. Studia Linguistica.

Reinhart, Tanja. 1997. Quantifier scope: How labor is divided between QR and choice functions. Linguistics and Philosophy 20 (4): 335-397. https://doi.org/10.1023/A:1005349801431

Sauerland, Uli, Jan Anderssen and Kazuko Yatsushiro. 2005. The plural is semantically unmarked. In S. Kepser and M. Reis (eds.), Linguistic Evidence: Empirical, Theoretical, and Computational Perspectives, 413-434. Berlin: Mouton de Gruyter. https://doi.org/10.1515/9783110197549.413

Schwarz, Florian. 2014. How Weak and How Definite are Weak Definites? In A. AguilarGuevara, B. Le Bruyn and J. Zwarts (eds.), Weak Referentiality, 213-235. Amsterdam, Philadelphia: John Benjamins. https://doi.org/10.1075/la.219.09sch.

Stark, Elisabeth. 2016. Nominal morphology and semantics - Where is gender (and partitive articles) in Gallo-Romance?. In S. Fisher and M. Navarro (eds.), Proceedings of the VII Nereus international workshop, 131-149. Konstanz: Fachbereich Sprachwissenschaft der Universität Konstanz.

Stark, Elisabeth and David Gerards. 2020. Partitive Articles in Aosta Valley Francoprovençal - Old Questions and New Data. In T. Ihsane (ed.), Bare Nouns vs. 'Partitive Articles': Disentangling Functions, 301-334. Leiden/Boston: Brill. https://doi.org/10.1163/9789004437500_010

Storto, Gianluca. 2003. On the status of partitive determiner in Italian. In J. Quer, J. Schroten, M. Scorretti, P. Sleeman and E. Verheugd-Daatzelaar (eds.), Romance Languages and Linguistic Theory 2001. Selected papers from Going Romance, Amsterdam, 6-8 December 2001, 315-330. Amsterdam: John Benjamins. https://doi.org/10.1075/cilt.245 
Vanelli, Laura. 2010. Ipotesi tipologiche sul friulano (e sul ladino dolomitico) su base morfologica: la formazione del plurale. In M. Iliescu, H. Siller-Runggaldier and P. Daniel (eds), Actes du XXV Congrès International de Linguistique et de Philologie Romanes (Innsbruck 2007), vol. 7, 123-33. Berlin, New York: De Gruyter. https://doi.org/10.1515/9783110231922.7-123

Wagiel, Marcin. 2018. Subatomic Quantification. Ph.D. thesis. Masaryk University of Brno.

Zamparelli, Roberto. 2008. Dei ex machina. A note on plural/mass indefinite determiners. Studia Linguistica 62: 301-327. https://doi.org/10.1111/j.14679582.2008.00149.x 